\title{
Bagging Organic Peaches Reduces Physical Injuries and Storage Decay with Minimal Effects on Fruit Quality
}

\author{
David Campbell, Ali Sarkhosh, and Jeffrey K. Brecht \\ Horticultural Sciences Department, University of Florida, 2550 Hull Road, \\ Gainesville, FL 32611 \\ Jennifer L. Gillett-Kaufman
Department of Entomology, Texas A\&M University, 370 Olsen Boulevard,
College Station, TX 77843
}

Oscar Liburd

Entomology and Nematology Department, University of Florida, 1881 Natural Area Drive, Gainesville, FL 32608

Juan Carlos Melgar

Department of Plant and Environmental Sciences, Clemson University, 105 Collings Street, Biosystems Research Complex 204, Clemson, SC 29634

\section{Danielle Treadwell \\ Horticultural Sciences Department, University of Florida, 2550 Hull Road, Gainesville, FL 32611}

Additional index words. brown rot, index of absorbance difference, low chill, Monilinia fructicola, Prunus persica, 'TropicBeauty', Zaprionus indianus

\begin{abstract}
Fruit bagging is an acceptable cultural practice for organic production that provides a physical barrier to protect fruit. It can reduce pest and pathogen injury for a variety of fruit crops, but quality attributes have been inconsistent for peach [Prunus persica (L.) Batsch] and other bagged fruit. A 2-year experiment on a U.S. Department of Agriculture (USDA) organiccertified peach orchard in central Florida was conducted to analyze the effects of a commercially available paper bag designed for fruit protection and cardinal quadrant (north, south, east, and west sides) of the tree canopy on low-chill peach 'TropicBeauty' fruit quality. Protective bags appeared to delay fruit maturity. Flesh firmness and chlorophyll concentration of bagged fruit were $31 \%$ and $27 \%$ greater than unbagged fruit, respectively. Bagged fruit were protected as demonstrated with a reduction in mechanical injury by $95 \%$, fruit fly injury by $450 \%$, and scablike lesions by $810 \%$. Bagging reduced fruit brown rot (Monilinia fructicola) at harvest and 7 days after harvest; unbagged fruit were 2 and 3.5 times more likely to have rot at harvest and 7 days after harvest, respectively. Fruit bags did not affect yield, fruit size, total soluble solids, titratable acidity, pH, peel lightness, peel hue angle, or flesh color. Overall, canopy cardinal quadrant location had minimal effect on fruit quality or fruit injury. These results demonstrate that bagging peach fruit protects against various pests and diseases but has minimal effects on fruit quality. Broad adoption of this technology is highly dependent on available labor, market demands, and profitability but may be suitable for producers using direct-to-consumer market channels.
\end{abstract}

Received for publication 9 Sept. 2020. Accepted for publication 26 Oct. 2020.

Published online 4 December 2020.

We thank Edzard van Santen, Professor of Agronomy and Director of the University of Florida Institute of Food and Agricultural Sciences Statistical Consulting Unit, for his statistical assistance. This work is supported by Organic Agriculture Research and Extension Initiative 2016-51300-25726 from the U.S. Department of Agriculture National Institute of Food and Agriculture. Any opinions, findings, conclusions, or recommendations expressed in this publication are those of the author(s) and do not necessarily reflect the view of the U.S. Department of Agriculture.

D.T. is the corresponding author. E-mail: ddtreadw@ ufl.edu.

This is an open access article distributed under the CC BY-NC-ND license (https://creativecommons. org/licenses/by-nc-nd/4.0/). harvested as early as mid-March (Olmstead et al., 2016) and satisfy a small portion of the early demand both locally and nationwide; however, organic peach producers have reported up to a $50 \%$ yield loss in the Southeast due to the lack of pest management tools that are compatible with organic production including reliable cultural practices and effective compliant pesticides (Blaauw et al., 2017). Different options to manage arthropod pests and diseases are needed to increase profitability in organic peach production and to meet market demand.

Fruit bagging is a cultural management practice that is used to protect fruit from arthropod pests and pathogens (Sharma et al., 2014). In China, bagging reduced russet and improved the visual quality of the fruit, while reducing Chlorpyrifos, Carbendazim, and Cyhalothrin pesticide residues on pear (Lin et al., 2008) and allergens in peach (Ma et al., 2018). Fruit bagging reduced anthracnose (Colletotrichum spp.) infection on mango (Mangifera indica L.) in Australia (Hofman et al., 1997). In addition to providing pest and pathogen protection, bagging can affect fruit quality. Peach bagging research has shown inconsistent effects on fruit quality characteristics such as size, titratable acidity (TA), total soluble solids (TSS), chlorophyll concentration, flesh color, peel color, firmness, phenolic compounds, and anthocyanin content in South Carolina (Allran et al., 2019), Italy (Baraldi et al., 1998), and China (Wang et al., 2010; Zhang et al., 2015).

In Florida, peach fruit are exclusively grown for the fresh market and blemish-free fruit are demanded by most consumers. Peach fruit quality is reduced by insect feeding with mandibulate (orthopteran), haustellate (hemipteran), and rasping (thysanopteran) mouthparts, as well as oviposition from weevils (coleopteran) and fruit flies (dipteran). Brown rot (Monilinia fructicola) and peach scab (Cladosporium carpophilum) are common fungal pathogens that reduce marketable yields for peach fruit in the Southeast (Blaauw et al., 2017). In the field, bags have been used to prevent oviposition of Caribbean fruit fly [Anastrepha suspense (Loew)] on mango 'Tommy Adkins' and 'Keitt' near Homestead, FL (Pena et al., 2006), but peach bagging research to reduce insect or pathogen injury is limited and has demonstrated mixed results in South Carolina (Allran et al., 2019). Although promising as a cultural practice to improve fruit quality and reduce decay and injury, evaluation of bagging with peach cultivars and organic production systems is needed to determine the suitability of the practice for Florida peach growers. Therefore, the objectives of this study were to evaluate the effects of bagging low-chill peach fruit on fruit quality, insect injury, pathogen injury, and decay. We also investigated how the location of the fruit, determined by cardinal quadrant of the tree canopy, was affected by bagging. 


\section{Materials and Methods}

Experimental site. On-farm trials were conducted on 'TropicBeauty' peaches in 2018 and 2019 at a USDA organic certified peach orchard in Lake County, FL (lat. $28.608826^{\circ} \mathrm{N}$, long. $-81.750942^{\circ} \mathrm{W}$, altitude $34 \mathrm{~m}$ ) that was operated as a U-pick business. The soil was a Candler Series (Hyperthermic, uncoated Lamellic Quartzipsamments), which is characterized as a deep, rapidly drained sand with low organic matter. The orchard was planted on a north-south slope and was surrounded by private residences on the south, east, and west with managed slash pine (Pinus elliottii Engelm.) and a grapefruit [Citrus paradisi (Macf.)] orchard to the north. The peach orchard was established in 2012 at a tree a density of 289 trees/ha. Trees were planted in east-west rows.

Each tree was pruned to an open vase shape and maintained with biannual pruning to a width of $2.1 \mathrm{~m}$ and a height of $1.8 \mathrm{~m}$. Orchard floor alleys were mowed regularly. The area under the canopy received straw mulch $(\approx 5 \mathrm{~cm}$ deep) in 2018 and a pine-oilbased herbicide but no mulch in 2019. In early January of both years, trees received $1121 \mathrm{~kg} \cdot \mathrm{ha}^{-1}$ of granular fertilizer $10 \mathrm{~N}-0.9 \mathrm{P}-$ 6.6K (Nature Safe 10-2-8; Griffin Industries, Cold Spring, KY) that was applied in bands in 2018 and broadcasted in 2019. Foliar applications of yeast extract at $7.0 \mathrm{~L} \cdot \mathrm{ha}^{-1}($ KeyPlex 350 OR; KeyPlex, Winter Park, FL) and water-soluble sulfate of potash at 11.1 $\mathrm{kg} \cdot \mathrm{ha}^{-1}$ were applied during the growing season to provide disease protection and address nutrient deficiencies.

Experimental design. The treatments were arranged in a randomized complete block design with four replicates and a splitplot restriction. The main factor, bagging treatment (see section on Bag installation and harvest), was assigned to whole trees and tested at two levels, bagged and unbagged. The subfactor, canopy quadrant, was evenly divided into north, south, east, and west cardinal directions around each tree. Replications or blocks were determined by scion trunk circumference measured $25 \mathrm{~cm}$ above the soil surface (minimum and maximum circumference was 24.6 and $48.0 \mathrm{~cm}$ ). Each replicate included six trees, three bagged and three unbagged, and the entire experiment included 24 trees.

Sampling. The orchard was sampled biweekly for known insect pests and symptoms of disease. Once known orthopteran insect pests reached the nominal/subjective threshold (Poston et al., 1983) determined by visual observations made by the grower, weekly foliar applications of insecticides were rotated to minimize risk of resistance. Products included rosemary oil, geraniol, and peppermint oil (KeyPlex Ecotrol Plus) at $2.5 \mathrm{~mL} \cdot \mathrm{L}^{-1}$ of water and PyGanic insecticide at $1.2 \mathrm{~mL} \cdot \mathrm{L}^{-1}$ of water applied to runoff. A fungicide containing the QST 713 strain of Bacillus subtilis (Serenade OPTI; Bayer, Whippany, NJ) was applied weekly at $2.52 \mathrm{~L} \cdot \mathrm{ha}^{-1}$. Products were applied up to $12 \mathrm{~h}$ before each harvest to account for preharvest intervals at labeled rates. Weekly sprays on both bagged and unbagged fruit occurred from 17 Mar. to 31 May in 2018 and from 10 Mar. to 15 May in 2019. Before budbreak, five branches per quadrant were identified per tree and served as the location for harvested fruit. Trees remained in the same block during 2018 and 2019 , but the treatments were randomized again in 2019.

Bag installation and harvest. Bag installation was modeled after methods previously described for peaches by Allran et al. (2019). Full bloom was observed on 10 Feb. 2018 and 29 Jan. 2019, and fruit were thinned according to standard grower practices (Chang et al., 2018). One day after the first organicapproved protective insecticide and fungicide were applied, 11 fruitlets in each quadrant on each designated tree were bagged on 18 Mar. 2018 and 2 Mar. 2019. Fruitlets measured between 3 to $4 \mathrm{~cm}$ along the stem-blossom axis. Bagging consisted of placing the entire fruitlet in a commercially available white paper bag $(15 \times 18 \mathrm{~cm})$ that was impregnated with a water resistant wax (Shijazhuang Yishun Package Machine Co., Shijazhuang, Hebei Province, China). The bag was constructed with a v-shaped notch and twist tie that was glued inside a folded portion of the bag. After placing the bag around the fruitlet, when the apex of the notch touched the branch, the portions of the bag that extended on the opposite side of the branch were cinched in an accordion-like fashion and secured with the twist-tie. The twist-tie was rotated at least $360^{\circ}$ around the cinched paper and the secured bag did not rotate around the branch when slightly agitated (Fig. 1). Based on grower recommendation, tactile observations of softening at fruit distal (blossom) ends, and increased blush of unbagged fruit were used to determine harvest times. Harvests occurred from 7 to 10 May in 2018 (two events) and 23 to 29 Apr. in 2019 (three events).

Meteorological, soil, and leaf nutrient data collection. Weather data for 2018 and 2019 were collected from the closest Florida Automated Weather Network (FAWN, 2019) weather station (lat. $28.681650^{\circ} \mathrm{N}$, long. $-81.885650^{\circ} \mathrm{W}$, altitude $27 \mathrm{~m}$ ), which was located $\approx 15.5 \mathrm{~km}$ northeast of the orchard. Soil and leaf tissue nutrient concentrations were assessed after fruit harvest to determine nutrient status to eliminate the possibility of any confounding factors. Along the slope gradient, soil was cored with a $2.5 \mathrm{~cm}$ diameter probe to $10 \mathrm{~cm}$ deep at three locations that were perpendicular to the slope. Six soil cores were collected for each location, bulked and mixed, and the samples were submitted to the University of Florida, Institute of Food and Agricultural Sciences (UF/ IFAS) Analytical Research Laboratory (Gainesville, FL) for analysis with a Mehlich-3 extraction. Thirty first fully expanded mature leaves and petioles from each tree were collected and submitted to Waypoint Analytical Laboratory (Mulberry, FL) for analysis.

Fruit quality analysis. Six fruit from each quadrant on each tree were randomly selected from tagged branches for quality analysis. Fruit were carefully packed in foam fruit trays and transported in a climate-controlled vehicle to the Postharvest Physiology Laboratory at UF/IFAS with all measurements conducted at room temperature $\left(24^{\circ} \mathrm{C}\right)$. Immediately upon arrival, fruit diameter measurements were taken from the midpoint of the fruit along the suture bulge and center of the cheeks using a digital caliper (EW-97152; Cole-Parmer, Vernon Hills, IL). Fresh weight was recorded with a digital scale (Mettler Toledo, Columbus, OH). Two measurements of peel color were taken from the center of each cheek using a colorimeter (Minolta CR400; Marunouchi, Chiyoda, Tokyo, Japan). Color lightness $\left(\mathrm{L}^{*}\right)$, hue angle, and chroma were either directly reported or calculated from the CIE $\mathrm{L}^{*} \mathrm{a}$ *b scale. Hue angle and chroma were calculated from the $a^{*}$ and $b^{*}$ values as $\tan ^{-1}\left(b^{*} / a^{*}\right)$ and as $\left[a^{*}+b^{*}\right]^{1 / 2}$, respectively. An indirect measurement of chlorophyll- $\alpha$ concentration was taken with a calibrated and indexed absorbance difference (DA) meter that measures the absorption difference between $670 \mathrm{~nm}$ and $720 \mathrm{~nm}$ (Spadoni et al., 2016; Sinteleia DA Meter, Bologna, Italy). Two DA measurements taken on the surface of the fruit at the center of each cheek were averaged for each fruit. Fruit were then stored in a $3{ }^{\circ} \mathrm{C}$ cold room overnight.

The next day, fruit were allowed to return to room temperature before collection of additional measurements. The midpoint of both cheeks along the stemblossom axis of two fruit per plot was peeled to expose a circular area of flesh $\approx 2.5 \mathrm{~cm}$ in diameter and $1 \mathrm{~mm}$ deep. This cut exposed the flesh and provided a smooth surface from which to measure the flesh color and flesh firmness. Two flesh color measurements were collected using identical methods and instruments as described for peel color measurements. Fruit flesh firmness was measured as maximum flesh resistance to penetration using an 8 -mm diameter metal convex-tip probe inserted to a depth of $8 \mathrm{~mm}$ (TA HQ plus texture analyzer; Texture Technologies, Inc., Hamilton, MA). Two longitudinal slices (approximately one-quarter of the total peach flesh and peel) were then removed along the stem-blossom axis with a clean knife and the samples were placed into a zipper-lock plastic freezer storage bags and held at $-30{ }^{\circ} \mathrm{C}$ until further analyses could be performed. The knife was cleaned with a single-use disposable towel between each plot.

Within $30 \mathrm{~d}$ of harvest, frozen fruit slices were thawed, blended (commercial blender; Hamilton Beach, Glen Allen, VA) until smooth, and centrifuged for $20 \mathrm{~min}$ at 22,217 $g_{\mathrm{n}}$ and $4{ }^{\circ} \mathrm{C}$ (Sorvall LYNX 400 centrifuge; Thermo Fisher Scientific, Waltham, MA). The supernatant was filtered through four layers of cheesecloth, collected in plastic scintillation vials, and held at $-30{ }^{\circ} \mathrm{C}$. Within $14 \mathrm{~d}$, supernatant samples were allowed to warm to room temperature, 
and $\mathrm{TA}$ and $\mathrm{pH}$ were measured using an automatic titrator (814 USB Sample Processor; Metrohm, Herisau, Switzerland). First, 3 $\mathrm{mL}$ of supernatant was diluted with $50 \mathrm{~mL}$ of deionized water and then titrated to a $\mathrm{pH}$ of 8.2 using a solution of $0.1 \mathrm{~mol} \cdot \mathrm{L}^{-1}$ sodium hydroxide (reported as a percentage of malic acid micro equivalents); the fruit $\mathrm{pH}$ was recorded as the initial measurement from the titrator. Total soluble solids were measured by pouring $\approx 0.5 \mathrm{~mL}$ of supernatant on the prism of an automatic refractometer (Reichert Ametek, Berwyn, PA).

Fruit insect and pathogen injury evaluation. Upon arrival in Gainesville, fruit for insect and pathogen injury evaluations were placed in a controlled environment storage room with an average of $19.3{ }^{\circ} \mathrm{C}$ and $\mathrm{RH}$ of $82.6 \%$ with sDs of 0.38 and 7.44 , respectively (HOBO MX2302A; Onset Computer, Bourne, MA). Fruit with suspected fungal lesions were submitted to the UF/IFAS Plant Diagnostic Center for pathogen identification. Fruit mechanical damage and scab-like lesions were assessed at harvest only; brown rot disease progression was assessed at harvest, $3 \mathrm{~d}$ after harvest, and $7 \mathrm{~d}$ after harvest. Four fruit from each quadrant from each tree (384 fruit each year) were inspected for mechanical damage, including peel with punctures and/or detached peel near the stem abscission layer. Pest or pathogen injury was identified as the presence or absence of an insect or fungal lesion. Insect damage was further attributed to the type of injury, including mandibulate, haustellate, or rasping feeding lesions. On the basis of the experience of the farmer collaborator, a rating scale was developed that reflected the buying
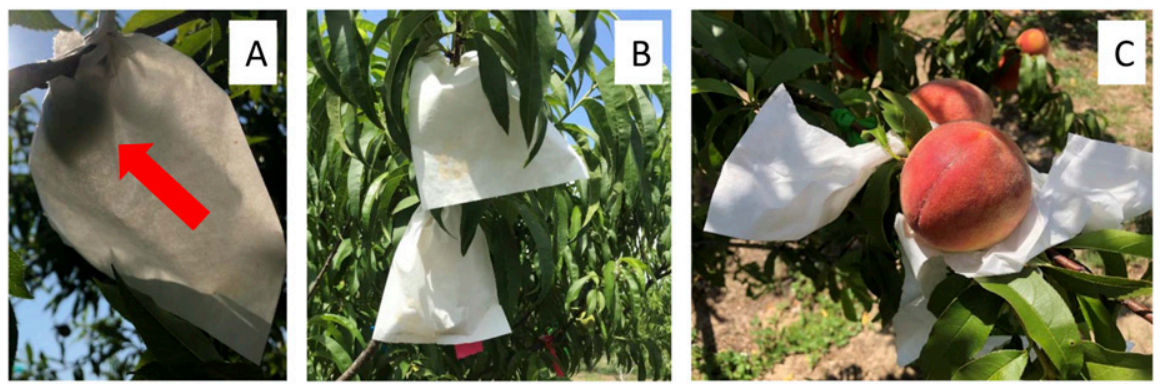

Fig. 1. Photographs of the cultural management practice of bagging to control insect pests and diseases for organic peach production in central Florida through the early season, red arrow pointing at a backilluminated growing peach, on 21 Mar. 2019 (A), midseason on 30 Mar. 2018 (B), and 2 d after bag removal on 2 May $2018(\mathbf{C})$.
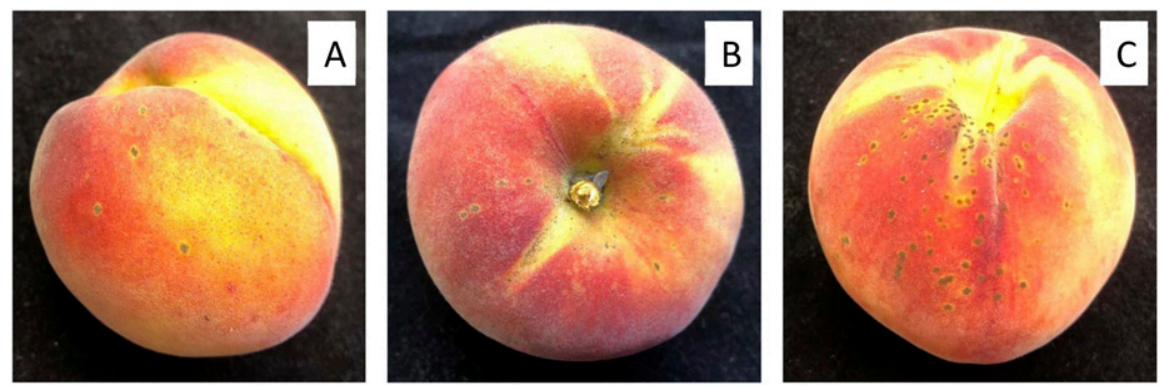

Fig. 2. Scale used to determine scab-like lesion severity for peaches grown in central Florida ranging from one to 10 lesions (A), between 11 and 20 lesions (B), and more than 20 lesions per fruit (C).

\section{Results}

Site conditions. The orchard naturally defoliated by 1 Dec. and first budbreak was observed on 10 Jan. Between 1 Dec. and 10 Jan., the orchard received 149 and 67 chill hours in 2018 and 2019, respectively. Chill hours were calculated by summing hours between 0 and $7.2{ }^{\circ} \mathrm{C}$ during dormancy. The chill hour accumulation was below the recommended amount of 150 chill hours for 'TropicBeauty' (Sarkhosh et al., 2018). Despite different blooming times in the two seasons of this study, the trees bore sufficient fruit at a similar developmental stage for appropriate comparisons. The average air temperature (measured at $2 \mathrm{~m}$ above the soil) and total precipitation for the growing cycle between full bloom and the first harvest were $18.2^{\circ} \mathrm{C}$ and $243.3 \mathrm{~mm}$ in 2018 and $19.4{ }^{\circ} \mathrm{C}$ and $207.3 \mathrm{~mm}$ in 2019 (Fig. 3). Optimal soil nutrient levels have not been determined for peach, but were uniform along the slope gradient and sufficient for citrus plant growth according to UF/IFAS recommendations in both years (Morgan et al., 2019; data not shown but will be available online at the UF dissertation repository in 2021). Leaf nutrient levels were adequate for optimum production (Johnson, 2008), similar to other leaf nutrient analysis of peach grown in Florida (Shahkoomahally et al., 2020), and did not differ between whole plot bagging treatment levels (data not shown).

Fruit physical and compositional attributes. Most physical and chemical fruit characteristics did not differ with bagging or by quadrant. There were no significant interactions between the main factors of bagging or quadrant and year for fruit diameter, fresh weight, DA Index, flesh firmness, TSS, $\mathrm{pH}$, or TA. Therefore, these data are presented with years combined (Table 1). Bagged fruit had a 0.1 greater DA Index $(P<0.01)$ score (DA Index score is a unitless measure), indicating a greater chlorophyll concentration. Bagged fruit had $6 \mathrm{~N}$ greater flesh firmness than unbagged fruit $(P$ $<0.01$ ). In addition, several measurements were significant for the main effect of year. Compared with 2019 , fruit in 2018 had $10 \%$ larger diameter $(P=0.03), 25 \%$ greater fruit fresh weight $(P=0.03), 6 \%$ greater TSS $(P<0.01)$, $9 \%$ greater TA $(P<0.01)$, and lower $\mathrm{pH}$ by 0.1 $(P=0.02)$. Bagging and quadrant did not affect fruit yield, fruit fresh weight, fruit diameter, TSS, TSS/TA ratio, or $\mathrm{pH}$.

Fruit peel and flesh color attributes. Peel lightness $(P<0.01)$ and peel hue $(P<0.01)$ showed a bagging by year interaction, and results are presented by year (Table 2). Analysis of peel lightness within year revealed that bagged peel was lighter than unbagged peel in 2018, but numerically the trends were reversed and no differences were detected in 2019. Analysis of peel hue within year did not detect any differences for bagging. Flesh chroma differed by year $(P<0.01)$ and quadrant $(P=0.02)$. Flesh was $7.0 \%$ more intense or saturated in 2019 compared with 2018 and $4.7 \%$ more intense or saturated in the east $($ chroma mean $=57.11)$ compared 


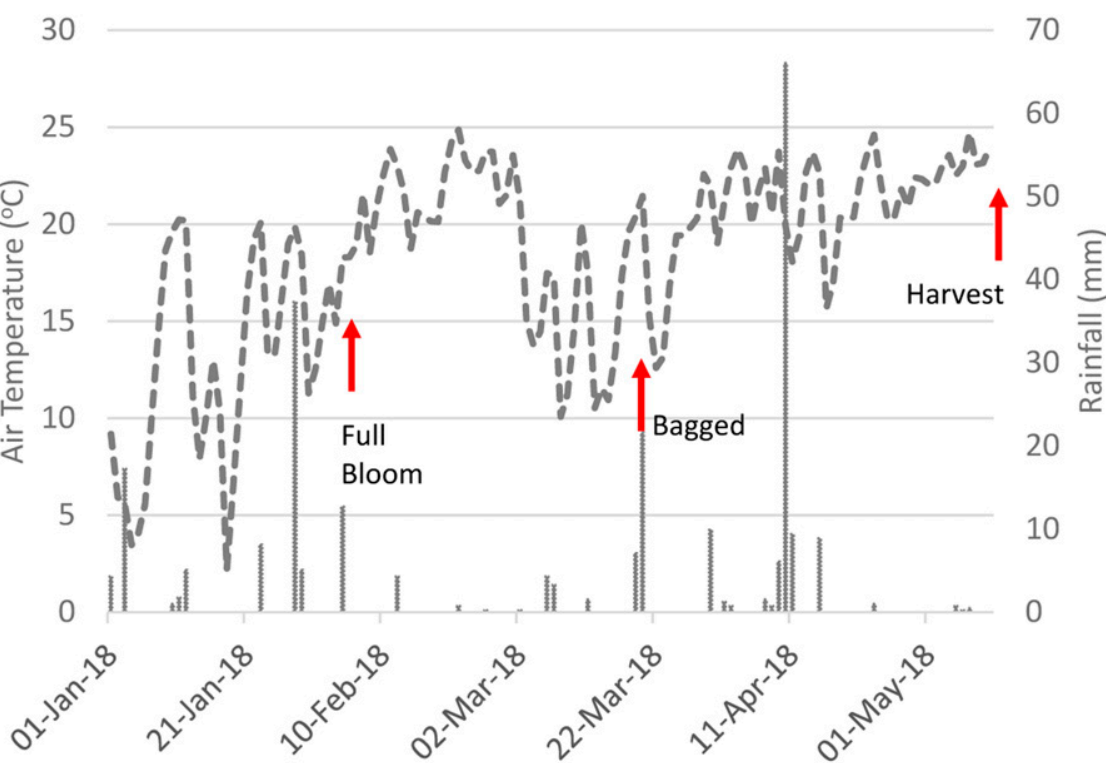

30

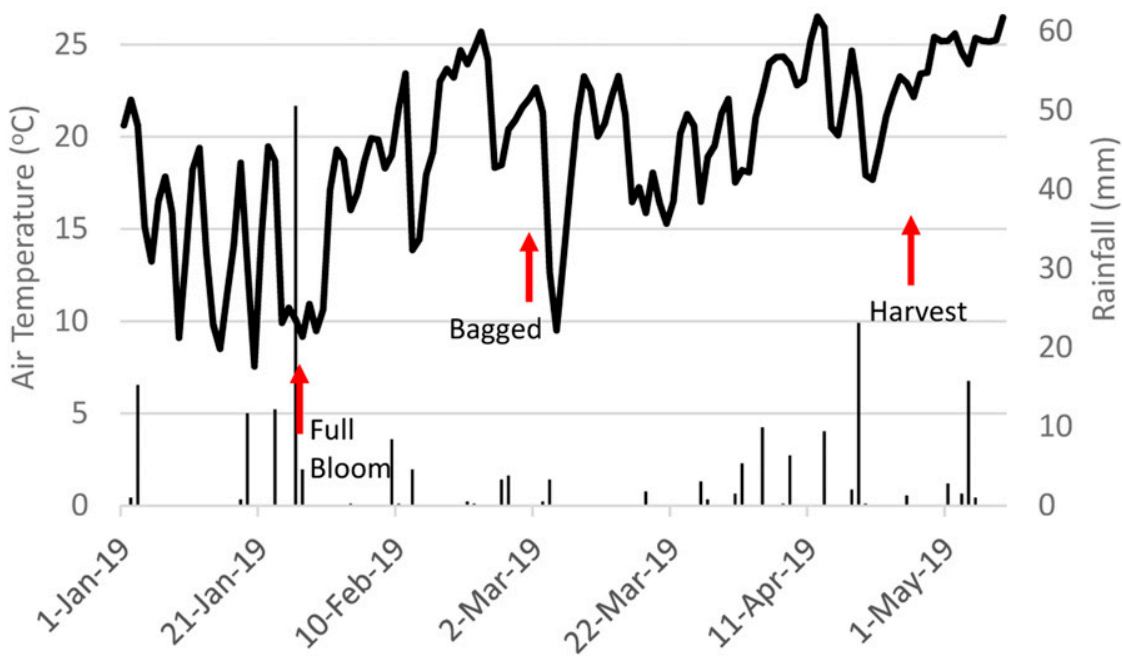

Fig. 3. Average daily temperature and rainfall in central Florida during peach fruit growth in (A) Spring 2018 (1 Jan. to 10 May) and (B) Spring 2019 (1 Jan. to 10 May).

with the north (chroma mean $=54.55)$. With years combined, peel chroma was $3.7 \%$ more saturated or intense in unbagged fruit than bagged fruit $(P<0.01)$.

Fruit insect and pathogen injury evaluation. Black circular lesions observed on fruit that resembled symptoms of peach scab (C. carpophilum) infection were not positively identified as $C$. carpophilum by the UF/IFAS Plant Diagnostic Center, therefore they are referred to as scab-like injury. The only bagging by year interaction observed was for scab-like injury $(P<0.01)$; therefore, results for all fruit injury measurements are presented by year for simplicity (Table 3, Fig. 4). Quadrant had no effect on fruit injury rating. Bagging fruit reduced mechanical injury by $3.9 \%$ compared with not bagging $(P=0.04)$. Mandibulate, haustellate, and rasping-type insect feeding injury was unaffected by bagging. Fruit fly [Zaprionus indianus (Gupta)] oviposition was not observed in 2019, but 11.5 were observed in 2018). Bagged fruit had fewer lesions for all scab-like severity levels than unbagged fruit $(P<0.01$ for all severity levels) (Table 4). For fruit that had at least one scab-like injury, the odds of having fruit with low, moderate, or severe injury was $9: 1,7: 1$, and $18: 1$ for unbagged vs. bagged fruit, respectively. At the low level of severity, bagged and unbagged fruit had a similar proportion of injured fruit with $75.0 \%$ and $73.5 \%$, respectively. At the moderate level of severity, bagged fruit had a greater proportion of injured fruit, averaging $19 \%$ vs. $14 \%$ for unbagged fruit. The trend was reversed at the highest severity level with unbagged fruit having a greater proportion of injury, averaging $12.5 \%$ vs. $6 \%$ for bagged fruit.

Fruit postharvest disease progression. Brown rot (M. fructicola) was confirmed by the UF/IFAS Plant Diagnostic Center as the primary postharvest fungal pathogen. Additional fungal pathogens were observed but were not attributed as the primary cause for rot. Only the main effect of bagging impacted postharvest disease progression and there was $17.4 \%$ more brown rot on unbagged fruit after $7 \mathrm{~d}$ postharvest $(P=0.04)$ (Fig. 4). Bagged fruit consistently exhibited a lower infection percentage of $M$. fructicola infection at harvest and $7 \mathrm{~d}$ after harvest. The odds of having fruit with rot were 3.5 and 2.0 times more likely for unbagged fruit at harvest and $7 \mathrm{~d}$ after harvest, respectively.

\section{Discussion}

Bagging effects on fruit physical, chemical, and compositional attributes. Past studies have shown mixed results for bagging on physical and compositional attributes for a variety of crops (Sharma et al., 2014). In this study, bagging did not affect the yield, fresh fruit weight, fruit diameter, TSS, TA, TSS/TA ratio, peel or flesh lightness, peel or flesh hue angle, or flesh chroma. Harvests for this experiment were conducted when fruit were tree ripened, and the significant reduction in mechanical injury may not be consistent with fruit harvested earlier. Tree-ripe fruit are softer than commercially harvested fruit that are shipped to distant markets. Shipped fruit with less mechanical injury will likely result in less fungal infection in the mechanically induced "open wounds." Under suboptimal conditions, excessive rot will result in juice leakage that contains pathogenic propagules onto proximal fruit, thus potentially reducing saleable product further. These results add to the body of literature with variable bagging results that are likely applicable to each crop, location, and bagging type/ duration.

In contrast to our study, Zhang et al. (2015) found that when white paper bags were left on peaches until harvest, the fruit attained higher weights, higher peel chroma, and lower peel lightness for 'Guibao' peach in China, but they found similar results for TSS and TA. When a single-layer black bag was removed from 'Guibao' fruit $15 \mathrm{~d}$ before harvest, the fruit size was similar to that of the 
Table 1. Physical and chemical characteristics of bagged and unbagged 'TropicBeauty' peaches grown in central Florida in 2018 and 2019.

\begin{tabular}{|c|c|c|c|c|c|c|c|c|c|}
\hline & Total yield $\left(\mathrm{kg} \cdot \mathrm{ha}^{-1}\right)$ & Fresh wt (g) & $\operatorname{Diam}(\mathrm{mm})$ & DA index ${ }^{z}$ & $\mathrm{TSS}^{\mathrm{y}}(\%)$ & $\mathrm{TA}^{\mathrm{x}}(\%)$ & TSS/TA & $\mathrm{pH}^{\mathrm{w}}$ & Flesh firmness $(\mathrm{N})$ \\
\hline Bagged & $4,203 \pm 571.1^{\mathrm{v}}$ & $99.0 \pm 7.0$ & $55.98 \pm 1.4$ & $0.47 \pm 0.03 \mathrm{a}$ & $11.82 \pm 0.13$ & $0.92 \pm 0.02$ & $13.35 \pm 0.02$ & 3.7 & $25.64 \pm 2.4 \mathrm{a}$ \\
\hline Unbagged & $3,896 \pm 571.1$ & $106.4 \pm 7.0$ & $57.41 \pm 1.4$ & $0.37 \pm 0.03 b$ & $11.81 \pm 0.13$ & $0.89 \pm 0.02$ & $14.41 \pm 0.02$ & 3.7 & $19.64 \pm 2.4 b$ \\
\hline$P$ value & 0.6731 & 0.3766 & 0.3630 & 0.0064 & 0.9962 & 0.0841 & 0.0869 & 0.8624 & 0.0058 \\
\hline
\end{tabular}

${ }^{\mathrm{z}}$ Unitless difference of absorbance (DA) index measurement of chlorophyll- $\alpha$ (Spadoni et al., 2016).

${ }^{\mathrm{y}} \mathrm{TSS}=$ total soluble solids.

${ }^{\mathrm{x}} \mathrm{TA}=$ titratable acidity.

${ }^{\mathrm{w}} \mathrm{pH}$ values represent the median.

${ }^{v}$ Values are the mean \pm SE. Within columns, different letters next to treatment means indicate significant differences at $P \leq 0.05$ as calculated by Tukey's honestly significant difference test.

Data were not separated by year due to lack of significance.

Table 2. Peel and flesh color attributes of bagged and unbagged 'TropicBeauty' peaches grown in central Florida in 2018 and 2019.

\begin{tabular}{|c|c|c|c|c|c|c|}
\hline & \multicolumn{3}{|c|}{ Peel } & \multicolumn{3}{|c|}{ Flesh } \\
\hline & $\mathrm{L}^{\mathrm{z}}$ & $\mathrm{h}^{\mathrm{y}}$ & $C^{x}$ & $\mathrm{~L}$ & $\mathrm{~h}$ & $\mathrm{C}$ \\
\hline \multicolumn{7}{|l|}{2018} \\
\hline Bagged & $54.13 \pm 1.3^{w}$ & $45.52 \pm 2.0$ & $42.46 \pm 0.9$ & $70.38 \pm 1.4$ & $80.25 \pm 0.9$ & $54.37 \pm 1.1$ \\
\hline Unbagged & $48.52 \pm 1.3$ & $40.45 \pm 2.0$ & $43.86 \pm 0.9$ & $68.86 \pm 1.4$ & $78.67 \pm 0.9$ & $54.60 \pm 1.1$ \\
\hline$P$ value & 0.0312 & 0.1022 & 0.2964 & 0.2175 & 0.0483 & 0.8756 \\
\hline \multicolumn{7}{|l|}{2019} \\
\hline Bagged & $48.79 \pm 0.9$ & $45.69 \pm 1.2$ & $43.45 \pm 0.7$ & $69.49 \pm 1.3$ & $82.08 \pm 0.9$ & $58.25 \pm 0.6$ \\
\hline Unbagged & $49.56 \pm 0.9$ & $47.37 \pm 1.2$ & $44.84 \pm 0.7$ & $68.67 \pm 1.3$ & $81.43 \pm 0.9$ & $58.10 \pm 0.6$ \\
\hline$P$ value & 0.4832 & 0.1179 & 0.2020 & 0.5485 & 0.5330 & 0.8474 \\
\hline
\end{tabular}

${ }^{\mathrm{z}} \mathrm{L}=$ Lightness range from 0 (black) to 100 (white).

${ }^{\mathrm{y}} \mathrm{h}=$ Hue angle that represents color ranging from 0 to 360 with colors equivalent to 0 (red), 90 (yellow), 180 (green), and 270 (blue).

${ }^{\mathrm{x}} \mathrm{C}=$ Chroma, color saturation or intensity from 0 (gray) to 60 (full saturation/intensity).

${ }^{\mathrm{w}}$ Values are the mean $\pm \mathrm{SE}$.

Table 3. Percent (\%) of injured fruit for bagged and unbagged 'TropicBeauty' peaches grown in central Florida in 2018 and 2019 , according to the type of injury recorded at harvest.

\begin{tabular}{|c|c|c|c|c|c|c|}
\hline & Fly Oviposition (\%) & Haustellate (\%) & Mandibulate (\%) & Mechanical (\%) & Rasping (\%) & Scab-like $(\%)$ \\
\hline \multicolumn{7}{|l|}{2018} \\
\hline Bagged & na & $2.6 \pm 0.01^{z}$ & $4.7 \pm 0.02$ & $4.2 \pm 0.04$ & $13.0 \pm 0.04$ & $5.7 \pm 0.03$ \\
\hline Unbagged & na & $2.6 \pm 0.01$ & $8.9 \pm 0.02$ & $8.3 \pm 0.04$ & $15.1 \pm 0.04$ & $59.4 \pm 0.03$ \\
\hline$P$ value & - & 1.0000 & 0.1488 & 0.3994 & 0.7540 & $<0.0001$ \\
\hline \multicolumn{7}{|l|}{2019} \\
\hline Bagged & $2.1 \pm 0.02$ & $7.8 \pm 0.03$ & $1.0 \pm 0.01$ & $6.3 \pm 0.03$ & $12.2 \pm 0.03$ & $2.6 \pm 0.03$ \\
\hline Unbagged & $11.5 \pm 0.02$ & $15.6 \pm 0.03$ & $3.3 \pm 0.01$ & $12.0 \pm 0.03$ & $8.9 \pm 0.03$ & $16.5 \pm 0.03$ \\
\hline$P$ value & 0.0009 & 0.0603 & 0.1856 & 0.1400 & 0.3824 & 0.0020 \\
\hline
\end{tabular}

${ }^{\mathrm{z}}$ Values are the mean $\pm \mathrm{SE}$.

na $=$ not applicable.

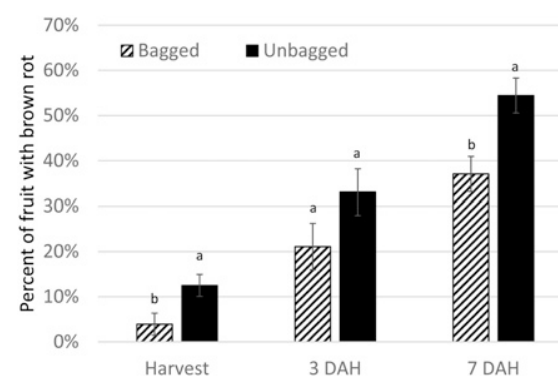

Fig. 4. Percentage of fruit (bars represent SE) with brown rot lesions at harvest $(P=0.0001), 3 \mathrm{~d}$ after harvest (DAH) $(P=0.1503)$, and $7 \mathrm{DAH}$ $(P=0.0400)$. Fruit were stored in a controlled environment room with an average temperature of $19.3{ }^{\circ} \mathrm{C}$ and relative humidity of $82.6 \%$ Percent at each observation time with the same letter above the SE bar are not significantly different at $P \leq 0.05$ as calculated by Tukey's honestly significant difference test.

control, and the fruit had the same color characteristics as fruit in white paper bags but had higher TSS than the controls. Ma et al. (2018) reported increased fresh weight and reduced TSS when 'Zaochunhong' peaches were bagged with a brown and black waxed paper bag. Lima et al. (2013) evaluated 16 peach cultivars in Brazil including 'TropicBeauty' and found that bagged 'TropicBeauty' had lower TSS at harvest but similar TA compared with unbagged 'TropicBeauty'. Tyas et al. (1998) found that white paper bags on 'Tai So' lychee [Litchi chinensis (Sonn.)] fruit in Australia had no effect on fruit fresh weight. They did find that bagging reduced the percentage of rejected fruit, decreased peel chroma if fruit were bagged at least $80 \mathrm{~d}$ before harvest, increased the hue angle in the upper canopy, decreased the TSS in the north-east quadrant, and decreased the Brix:acid ratio (TSS/TA) for the northeast and northwest quadrants. Other studies that did not specify the bag color or had a white outer bag with a different colored inner bag generally found inconsistent differences in color, TSS, and TA for bagged 'Delicious', 'Granny Smith', and 'Golden Delicious' apples [Malus $\times$ domestica (Borkh.)] (Ju et al., 1998; Liu et al., 2013; Wang et al., 2013) and 'Cuiguan' and 'Housi' pears (Pyrus communis L.) (Lin et al., 2008). The lack of significant differences for the peaches in our study could be considered as a positive result suggesting that bagging does not negatively affect fruit quality for some varieties of peaches.

Bagging effects on fruit maturation. Peach maturation is associated with an increase in ethylene concentration leading to physiological changes that result in a concurrent reduction in firmness and chlorophyll concentration (Chapman et al., 1991). At harvest, both the chlorophyll concentration and flesh firmness were $27 \%$ and $30 \%$ greater, respectively, for bagged peaches than unbagged peaches, which suggests that bagging delayed maturation. Zhang et al. (2015) found similar firmness results when bagging peaches in white paper bags but did not detect differences when using white polypropylene bags or black paper bags. In contrast, when Wang et al. (2010) bagged the late-ripening peach 'Wami' in China with a two-layered paper bag (black inner and brown outer), they found that bagging accelerated fruit maturation as evidenced by earlier production of the major contributors to peach 
Table 4. Count of fruit injured by scab-like injuries for bagged and unbagged 'Tropic Beauty' peaches grown in central Florida in 2018 and 2019 , according to the number of lesions recorded at harvest.

\begin{tabular}{|c|c|c|c|c|c|c|c|c|}
\hline & \multicolumn{2}{|c|}{ None $^{z}$} & \multicolumn{2}{|c|}{ Low $^{\mathrm{y}}$} & \multicolumn{2}{|c|}{ Moderate $^{x}$} & \multicolumn{2}{|c|}{ Severe $^{\mathrm{w}}$} \\
\hline & No. ${ }^{v}$ & Prop. $^{\text {u }}$ & No. & Prop. & No. & Prop. & No. & Prop. \\
\hline$\overline{\text { Bagged }}$ & $181.5 \pm 9.5$ & na & $6.0 \pm 1.7$ & $75 \%$ & $1.5 \pm 0.9$ & $19 \%$ & $0.5 \pm 0.5$ & $6 \%$ \\
\hline Unbagged & $117.0 \pm 7.7$ & na & $53.0 \pm 5.2$ & $73.5 \%$ & $10.0 \pm 2.2$ & $14 \%$ & $9.0 \pm 2.1$ & $12.5 \%$ \\
\hline$P$ value & $<0.0001$ & & $<0.0001$ & & $<0.0001$ & & $<0.0001$ & \\
\hline
\end{tabular}

${ }^{\mathrm{z}}$ None $=0$ lesions

${ }^{\mathrm{y}}$ Low $=1$ to 10 lesions.

${ }^{\mathrm{x}}$ Moderate $=11-20$ lesions

${ }^{\mathrm{w}}$ Severe $=21+$ lesions.

${ }^{\mathrm{v}}$ Value are the count mean $\pm \mathrm{SE}$.

${ }^{\mathrm{u}}$ Prop. = Proportion of injuries as a count of fruit at each scab-like severity level divided by all fruit with at least one scab-like injury.

aroma, namely $\gamma$-hexalactone and $\delta$-decalactone.

Bagging other crops with a variety of bagging materials has revealed delayed maturation of 'Nam Dok Mai \#4' mangoes in Thailand (Chonhenchob et al., 2010) and 'Zaghloul' date palm (Phoenix dactyliferai L.) fruit in Egypt (Kassem et al., 2011). In contrast, other researchers observed that bagging accelerated maturation time for 'Laetitia' plums [Prunus salicina (Lindell)] in South Africa (Murray et al., 2005) and 'Fuji' apples in the United States (Fan and Mattheis, 1998). Bagging had no effect on firmness for 'Harumanis' mangoes in Malaysia (Ding and Syakirah, 2010) and 'Cuiguan' or 'Housi' pears ( $P$. communis L.) in China (Lin et al., 2008).

Other bagging materials have been shown to affect the maturation timeframe, as Debnath and Mitra (2008) found a 12-d accelerated maturation when using cellophane paper bags and a 10-d delayed maturation when using brown paper or newspaper bags on 'Bombai' lychee. Overall, the effect of bagging appears to be dependent on the crop including variety, bagging duration, and bagging type. For the Florida organic peach shipping market, delayed maturation combined with small fruit size may hinder the success of this market option, but it may be beneficial for U-pick operations that desire to extend the harvesting season.

Bagging effects on pathogen and insect injury. Physical exclusion of pests and pathogens can prevent fruit injury and increase marketable yields (Sharma et al., 2014). The reduction in scab-like lesions at harvest is necessary for customers that desire blemishfree fruit. For customers that are unwilling to accept limited scab-like injury, bagging may increase the potential marketable yield. Bags have reduced fungal infection for other fruits such as: Colletotrichum spp. and Dothoriella spp. on 'Keitt' mangoes in Australia (Hofman et al., 1997), Alternaria kikuchiana on mango in Japan (Kitagawa et al., 1992), Colletotrichum gloeosporioides on 'Jingkwang' mangoes in Taiwan (Senghor et al., 2007), and Colletotrichum spp. on mango in Thailand (Chonchenchob et al., 2010). Allran et al. (2019) found inconsistent protective results, likely resulting from a delay in bagging that washed off the protective OMRI-approved spray applications, for bagged organically grown 'Crimson Lady' peach in Monetta, SC. The persistent reduction of rot at $19.3{ }^{\circ} \mathrm{C}$ for up to $7 \mathrm{~d}$ after harvest provides evidence that the bag effectively blocked spore contact with the fruit surface and may allow for an increased postharvest storage time. Bagging does not always promote an increased postharvest protection for all diseases and disorders, as Amarante et al. (2002) found that bagging did not affect the incidence of senescent breakdown or diseases after 6 months in cold storage for 'Doyenne du comice' pears in New Zealand.

The most injurious pest noted by the farmer collaborator in this study were stink bugs and other insects that damage fruit by haustellate feeding habits. Studies that demonstrate protection from insect pests are limited, but our finding that haustellate feeding injury was reduced at $P<0.10$ is positive and suggests that further protection may be achieved with modifications to bagging type or duration. The observed reduction in fruitfly damage is consistent with findings from previous studies (Bilck et al., 2011; Pena et al., 2006). The fruit-fly found in this study, $Z$. indianus, is a generalist known to feed on fallen fruit (van der Linde et al., 2010), but all specimens were collected from fruit still on the tree, which suggests that either the delayed maturity reduced larval feeding or the bag provided an effective physical barrier to the fruit fly. It should be noted that the fruit with larval holes were similar in weight and size to other bagged fruit in 2019 but had a 0.15 lower DA index, suggesting that the fruit with oviposition injury were more mature. Bagging effectively reduced anar butterfly [Deudorix Isocrates (Fab.)] oviposition injury from $90 \%$ to less than $10 \%$ for pomegranate (Puncia granatum L.) in Gujarat, India (Bagle, 2011). Reductions of stalk-end borer [Conopomorpha cramerellai (Snellen)] and stone borer (Platypepla spp.) infections have been reduced from $18.1 \%$ in the control group to $3.6 \%$ for bagged lychee in West Bengal, India (Debnath and Mitra, 2008).

Quadrant effects on fruit quality. Spatial arrangement of trees may improve the photosynthetic rate and other biochemical processes (Nerozzi et al., 1997) while simultaneously affecting the movement of arthropod pests and pathogens. The lack of differences between quadrants may be due to the low tree planting density that is more suitable for this working U-pick farm. Researchers in this study could easily traverse the tree row between trees for $\approx 70 \%$ of the trees in this study. The increased fruit and leaf light interception between trees may have created a similar environment on all sides of the tree. Although there were differences in flesh chroma among quadrants, no consistent pattern was found to suggest that cardinal direction in this orchard had an impact that is biologically relevant. The increased spacing between trees may also explain the lack of differences in fungal infection due to increased air flow and reduced leaf wetness between trees. Although arthropod pests were present in the orchard, the increased tree spacing would require flight between trees and may have provided an equal opportunity for insects to travel to any side of the tree.

Practical considerations of bagging. In this study, the effects of bagging peaches were evaluated against a control group where all peaches were protected by the most effective organic integrated pest and disease management program designed for Florida peach producers to date. Given our study design, additional research evaluating the difference between injury of bagged and unbagged fruit with reduced protection will be useful for creating a comprehensive plan that incorporates bagging and reduced pesticide applications. The off-setting effects of bagging on marketable yield, production cost, and sale price needs to result in a positive cash flow to be adopted by farmers. On one occasion each year, labor received $\approx 1 \mathrm{~h}$ of verbal instruction and hands-on practice bagging fruit and were timed over the course of installing or removing bags on two trees. We installed and removed 2.5 and 48 individual fruit bags per minute, respectively, but bagging time differs between fruit and bag type as evidenced that bag installation for lychee was 0.21 bags per minute (Debnath and Mitra, 2008). Incorporating bagging as a cultural management practice will require additional labor and the current trend of labor scarcity may be an insurmountable hurdle for adoption. If an appropriately sized labor force is available, then a grower with a market that demands a high-quality fruit, with an increased perceived value may be interested in fruit bagging in the Southeast.

\section{Conclusion}

Bagging slightly delayed peach maturity but had minimal impacts on fruit quality. Insect and fungal pathogen protection was observed for fruit fly, brown rot, and scab-like lesions with a trend for reductions in other pests that suggests additional protection may be possible with refined protocols and materials. At this 
time and in the foreseeable future, bagging is dependent on manual labor. Labor availability, production costs, and increased price for peach grown in bags need to be considered for each market opportunity.

\section{Literature Cited}

Allran, J., G. Schnabel, and J.C. Melgar. 2019. Peach bagging in the southeastern US. J. Amer. Pomol. Soc. 73:38-46. <https://pdfs.semanticscholar.org/c15d/ f08227a5e9a0cbdb44b9416e938e63f08f70.pdf\#pag$\mathrm{e}=40>$.

Amarante, C., N.H. Banks, and S. Max. 2002. Effect of preharvest bagging on fruit quality and postharvest physiology of pears (Pyrus communis). N. Z. J. Crop Hort. Sci. 30:99107, doi: 10.1080/01140671.2002.9514204.

Bagle, B.G. 2011. Studies on varietal reaction, extent of damage and management of anar butterfly, Deudorix (= Virachola) Isocrates Fab., in pomegranate. Acta Hort. 890:557559, doi: 10.17660/ActaHortic.2011.890.78.

Baraldi, R., F. Rapparini, A. Rotondi, and G. Bertazza. 1998. Effects of simulated light environments on growth and leaf morphology of peach plants. J. Hort. Sci. Biotechnol. 73:251258, doi: 10.1080/14620316.1998.11510972.

Bilck, A.P., S.R. Roberto, M.V.E. Grossmann, and F. Yamashita. 2011. Efficacy of some biodegradable films as pre-harvest covering material for guava. Scientia Hort. 130:341-343, doi: 10.1016/j.scienta.2011.06.011.

Blaauw, B., P. Brannen, B. Bellinger, D. Lockwood, and D. Ritchie. 2017. Southeastern peach, nectarine and plum pest management and culture guide. Bul. 1171. University of Georgia Cooperative Extension Service. $<$ http://extension.uga.edu/publications/detail.html?number=B1171>.

Chang, Y., A. Sarkhosh, J. Brecht, and P. Anderson. 2018. Thinning Florida peaches for larger fruit. HS1324. University of Florida Institute of Food and Agricultural Sciences, Gainesville. $<$ https://edis.ifas.ufl.edu/hs1324>.

Chapman, Jr., G.W., R.J. Horvat, and W.R. Forbus, Jr. 1991. Physical and chemical changes during the maturation of peaches (cv. Majestic). J. Agr. Food Chem. 39:867-870, doi: 10.1021/ jf00005a010.

Chonhenchob, V., D. Kamhangwong, J. Kruenate, K. Khongrat, N. Tangchantra, U. Wichai, and S.P. Singh. 2010. Preharvest bagging with wavelength-selective materials enhances development and quality of mango (Mangifera indica L.) cv. Nam Dok Mai \#4. J. Sci. Food Agr. 91:664-671, doi: 10.1002/jsfa.4231.

Debnath, S. and S.K. Mitra. 2008. Panicle bagging for maturity regulation, quality improvement and fruit borer management in litchi (Litchi chinensis). Acta Hort. 773:201-208, doi: 10.17660/ActaHortic.2008.773.29.

Ding, P. and M.N. Syakirah. 2010. Influence of fruit bagging on postharvest quality of 'Harumanis' mango (Mangifera indica L.). Acta Hort. 877:169-174, doi: 10.17660/ActaHortic.2010.877.15.

Fan, X. and J.P. Mattheis. 1998. Bagging 'Fuji' apples during fruit development affects color development and storage quality. HortScience 33:1235-1238, doi: 10.21273/HORTSCI.33.7.1235.

FAWN. 2019. Florida Automated Weather Network report generator. University of Florida, Gainesville, Florida. 6 May 2019. <http:// fawn.ifas.ufl.edu/data/reports/>.

Hofman, P.J., L.G. Smith, D.C. Joyce, G.I. Johnson, and G.F. Meiburg. 1997. Bagging of mango (Mangifera indica cv. 'Keitt') fruit influences fruit quality and mineral composi- tion. Postharvest Biol. Technol. 12:83-91, doi: 10.1016/S0925-5214(97)00039-2.

Johnson, R.S. 2008. Nutrient and water requirements of peach trees, p. 303-321. In: D.R. Layne and D. Bassi (eds.). The peach: Botany, production and uses. CAB International, Cambridge, MA.

Ju, Z., Y. Duan, and Z. Ju. 1998. Effects of covering the orchard floor with reflecting films on pigment accumulation and fruit coloration in 'Fuji' apples. Scientia Hort. 82:47-56, doi: 10.1016/S0304-4238(98)00161-7.

Kassem, H.A., A.K.H. Omar, and M.A. Ahmed. 2011. Response of Zaghloul date palm productivity, ripening and quality to different polyethylene bagging treatments. J. Agr. Environ. Sci. 11:616-621. <https://www.researchgate. net/profile/Alaa_Omar4/publication/231814846_ Response_of_Zaghloul_Date_Palm_Productivity_ Ripening_andQuality_to_Different_Polyethylene_ Bagging_Treatments/links/0deec531cc6dd1297a 000000.pdfs.

Kitagawa, H., K. Manabe, and E.B. Esguerra. 1992. Bagging of fruit on the tree to control disease. Acta Hort. 321:871-875, doi: 10.17660/ ActaHortic.1992.321.110.

Lima, A.D.J.B., Â.A. Alvarenga, M.R. Malta, D. Gebert, and E.B.D. Lima. 2013. Chemical evaluation and effect of bagging new peach varieties introduced in southern Minas GeraisBrazil. Food Sci. Tech. 33:434-440, doi: 10.1590/S0101-20612013005000077.

Lin, J., Z. Chang, Z. Yan, and X. Li. 2008. Effects of bagging on the quality of pear fruit and pesticide residues. Acta Hort. 772:315-318, doi: 10.17660/ActaHortic.2008.772.52.

Liu, Y., X. Zhang, and Z. Zhao. 2013. Effects of fruit bagging on anthocyanins, sugars, organic acids, and color properties of 'Granny Smith' and 'Golden Delicious' during fruit maturation. Eur. Food Res. Technol. 236:329-339, doi: 10.1007/s00217-012-1896-3.

Ma, Y., X. Zhao, H. Ren, H. Wu, M. Guo, Y. Zhang, Z. He, J. Han, and R. Tong. 2018. Significant reduction of the expression of peach (Prunus persica L. Batsch) allergen-encoding genes by fruit bagging with opaque paper. J. Agr. Food Chem. 66:4051-4061, doi: 10.1021/ acs.jafc. 8b00207.

Morgan, K.T., D.M. Cadyampakeni, M. Zekri, A.W. Shumann, T. Vashisth, and T.A. Obreza. 2019. 2019-2020 Florida citrus production guide: Nutrition management for citrus trees. CMB13. University of Florida Institute of Food and Agricultural Sciences, Gainesville. $<$ https://edis.ifas.ufl.edu/cg091>

Murray, X.J., D.M. Holcroft, N.C. Cook, and S.J.E. Wand. 2005. Postharvest quality of 'Laetitia' and 'Songold' (Prunus salicina Lindell) plums as affected by preharvest shading treatments. Postharvest Biol. Technol. 37:81-92, doi: 10.1016/j.postharvbio.2005.02.014.

Nerozzi, F., F. Rossi, O. Facini, and T. Georgiadis. 1997. Light transmittance and sunlit leaf area estimation in a peach canopy. J. Hort. Sci. 72:271-283. https://www.tandfonline.com/doi/abs/ 10.1080/14620316.1997.11515514>

Olmstead, M., J. Chaparro, P. Anderson, J. Williamson, and J. Ferguson. 2016. Florida peach and nectarine varieties. Circ. 1159. University of Florida Institute of Food and Agricultural Sciences, Gainesville. <http://edis.ifas.ufl.edu/mg374>.

Perez, A. and K. Plattner. 2013. Fruit and tree nuts outlook: Commodity highlight. Organic fruit and berries. USDA Economic Research Service. FTS-356SA. <https://www.ers.usda.gov/ publications/pub-details/?pubid=37054>.
Pena, J.E., W.P. Gould, M.K. Hennessey, G.J. Hallman, and J.H. Crane. 2006. Laboratory and field infestation studies on immature green 'Tommy Atkins' and 'Keitt' mangoes to determine host status to the Caribbean fruit fly (Diptera: Tephritidae). Proc. Annu. Meet. Fla. State Hort. Soc. 119:16-20. <https://journals.flvc.org/fshs/article/view/86070/82986>.

Poston, F.L., L.P. Pedigo, and S.M. Welch. 1983. Economic injury levels: Reality and practicality. Bull. Entomol. Soc. Amer. 29:49-53, doi: 10.1093/besa/29.1.49.

Sarkhosh, A., M. Olmstead, J. Chaparro, P. Anderson, and J. Williamson. 2018. Florida Peach and Nectarine Varieties. Circ. 1159. University of Florida Institute of Food and Agricultural Sciences, Gainesville. $<$ https://edis.ifas.ufl.edu/mg374>.

Senghor, A.L., W.J. Liang, and W.C. Ho. 2007. Integrated control of Colletotrichum gloeosporioides on mango fruit in Taiwan by the combination of Bacillus subtilis and fruit bagging. Biocontrol Sci. Technol. 17:865-870. https://www.tandfonline. com/doi/full/10.1080/09583150701527409.

Shahkoomahally, S., J.X. Chaparro, T.G. Beckman, and A. Sarkhosh. 2020. Influence of rootstocks on leaf mineral content in the subtropical peach cv. UFSun. HortScience 55:496-502, doi: 10.21273/HORTSCI14626-19.

Sharma, R.R., S.V.R. Reddy, and M.J. Jhalegar. 2014. Pre-harvest fruit bagging: A useful approach for plant protection and improved post-harvest fruit quality. J. Hortic. Sci. Biotechnol. 89:101-113, doi: 10.1080/14620316.2014.11513055.

Spadoni, A., I. Cameldi, M. Noferini, E. Bonora, G. Costa, and M. Mari. 2016. An innovative use of DA-meter for peach fruit postharvest management. Scientia Hort. 201:140-144, doi: 10.1016/S03044238(97)00125-8.

Tyas, J.A., P.J. Hofman, S.J. Underhill, and K.L. Bell. 1998. Fruit canopy position and panicle bagging affects yield and quality of 'Tai So' lychee. Scientia Hort. 72:203-213, doi: 10.1016/S0304-4238(97)00125-8.

USDA NASS. 2012. 2011 Certified Organic Production Survey. United States Department of Agriculture, National Agricultural Statistics Service. $<$ https://www.nass.usda. gov/Surveys/Guide_to_NASS_Surveys/Organic_ Production/>.

USDA NASS. 2017. Noncitrus fruits and nuts 2016 summary. United States Department of Agriculture, National Agricultural Statistics Service. $\quad<$ https://www.nass.usda.gov/Surveys/ index.php>.

van der Linde, K. 2010. Zaprionus indianus: Species identification and taxonomic position. Dros. Inf. Serv. 93:95-98. <http://www.academia.edu/download/30763201/van_der_Linde_ 95.pdf $>$.

Wang, L., X. Zhang, Y. Liu, X. Shi, Y. Wang, C. Zhang, and Z. Zhao. 2013. The effect of fruit bagging on the color, phenolic compounds and expression of the anthocyanin biosynthetic and regulatory genes on the 'Granny Smith' apples. Eur. Food Res. Technol. 237:875-885, doi: 10.1007/s00217-013-2055-1.

Wang, Y., C. Yang, C. Liu, M. Xu, S. Li, L. Yang, and Y. Wang. 2010. Effects of bagging on volatiles and polyphenols in 'Wanmi' peaches during endocarp hardening and final fruit rapid growth stages. J. Food Sci. 75:S455-S460, doi: 10.1111/j.1750-3841.2010.01817.x.

Zhang, B.B., J.Y. Guo, R.J. Ma, Z.X. Cai, J. Yan, and C.H. Zhang. 2015. Relationship between the bagging microenvironment and fruit quality in 'Guibao' peach [Prunus persica (L.) Batsch]. J. Hort. Sci. Biotechnol. 90:303-310, doi: 10.1080/14620316.2015.11513187. 